Histoire de l'éducation

147 | 2017

Les lieuX de l'enseignement technique $\left(\mathrm{XIX}^{\mathrm{e}}-\mathrm{XX}^{\mathrm{e}}\right.$ siècles)

\title{
Carole Christen, Laurent Besse (dir.), Histoire de l'éducation populaire - 1815-1945 - Perspectives françaises et internationales
}

Lille, Presses universitaires du Septentrion, 2017

Léo Vennin et Sidonie Rancon

\section{(2) OpenEdition}

Journals

Édition électronique

URL : https://journals.openedition.org/histoire-education/3324

DOI : 10.4000/histoire-education.3324

ISSN : 2102-5452

Éditeur

ENS Éditions

Édition imprimée

Date de publication : 30 juin 2017

Pagination : 202-204

ISSN : 0221-6280

Référence électronique

Léo Vennin et Sidonie Rancon, «Carole Christen, Laurent Besse (dir.). Histoire de l'éducation populaire 1815-1945 - Perspectives françaises et internationales », Histoire de l'éducation [En ligne], 147 | 2017, mis en ligne le 30 juin 2017, consulté le 20 mai 2021. URL : http://journals.openedition.org/histoireeducation/3324; DOI : https://doi.org/10.4000/histoire-education.3324

Ce document a été généré automatiquement le 20 mai 2021

(c) Tous droits réservés 


\title{
Carole Christen, Laurent Besse
} (dir.), Histoire de l'éducation populaire - 1815-1945 - Perspectives françaises et internationales

Lille, Presses universitaires du Septentrion, 2017

\author{
Léo Vennin et Sidonie Rancon
}

\section{RÉFÉRENCE}

Carole Christen, Laurent Besse (dir.), Histoire de l'éducation populaire - 1815-1945 -

Perspectives françaises et internationales, Lille, Presses universitaires du Septentrion, 2017

1 Issu d'un colloque tenu en 2015 à l'université Lille 3, cet ouvrage a pour ambition de faire un bilan des recherches historiques menées depuis une trentaine d'années sur le vaste ensemble de l'éducation populaire. Cette entreprise menée par Carole Christen et Laurent Besse ne vise pas à la synthèse générale ou à l'étude exhaustive de l'éducation populaire de 1815-1945, mais entend « dégager ses spécificités, ses enjeux, ses objectifs, ses pratiques, ses méthodes, et identifier ses acteurs au cours de cette période ». S'appuyant sur une historiographie en plein renouvellement, cet ouvrage se singularise par la confrontation des regards d'historiens, de politistes, de juristes, de chercheurs en sciences de l'éducation, de l'information et de la communication, d'archivistes conservateurs, etc.

Vingt-huit contributions viennent nourrir les réflexions : l'ouvrage est divisé en cinq grandes parties, dont un préambule s'intéressant à la définition de l'objet " éducation populaire » et quatre parties basées sur une approche chrono-thématique. Le préambule rappelle le caractère protéiforme de l'objet traité, rendant compte à la fois de son aspect foisonnant, changeant et éclaté. Un des enjeux de l'ouvrage étant d'ailleurs de pouvoir inclure des travaux de recherche portant « au sens large » sur 
l'éducation populaire, en montrant l'intérêt de l'intégrer plus foncièrement à l'histoire de l'éducation.

3 Une première partie interroge les portées politiques des pratiques de l'éducation populaire, du point de vue des intentions et des projets soutenus. Les différents articles regroupés ici montrent notamment la variété tout autant que les ambivalences et les controverses en jeu dans la réalisation de ces différents projets. Comme l'introduit Laurent Besse, ces projets, autant associés au mutualisme qu'à la coopérative, demeurent inscrits dans une visée de changement social radical tout en gardant la volonté de conciliation des classes. C'est cette ambivalence qui sera travaillée dans les différentes contributions, du point de vue des outils et des pratiques pédagogiques développées, tels que la lecture publique des lois, le catéchisme politique ou encore la goguette et les cours du soir. Sont aussi données à voir les imbrications entre pratiques pédagogiques et projets politiques, dans différents contextes, tel que l'impulsion du libéralisme naissant durant les années 1820 , le projet d'éducation politique de Parent au Québec ou encore le projet de l'école sociétaire associant les idées de Fourier et les conceptions pédagogiques de Pestalozzi en France.

Dès le début du XIX ${ }^{e}$ siècle, l'éducation populaire a aussi concerné les femmes, ce à quoi s'intéresse la deuxième partie de l'ouvrage, intitulée «le peuple au féminin ». Les contributions s'attachent essentiellement à l'étude d'initiatives en direction des femmes, telles que la création d'écoles et de cours pour les filles pauvres et cherchent à questionner leur place en tant qu'actrices de l'éducation populaire. Ce champ historiographique reste encore peu exploré, d'où le grand intérêt des contributions ici réunies.

5 La troisième partie intitulée "Intégrer le peuple » permet d'appréhender le début du $\mathrm{XX}^{\mathrm{e}}$ siècle comme une période de renouveau pour l'éducation populaire. L'étude du post-scolaire, notamment autour des conférences populaires, des causeries et des cours pour adolescents et adultes, ainsi que la description d'expériences d'universités populaires, en France et en Belgique, permettent d'interroger les réponses apportées par l'éducation populaire à la question sociale. Si l'éducation populaire, en cette décennie, vise majoritairement à conserver l'ordre social et les institutions républicaines, c'est précisément cette volonté d'intégration à la société qui est refusée par les parties du monde ouvrier qui perçoivent l'éducation populaire comme une forme de soutien à la société bourgeoise qu'elle combat.

6 L'ouvrage s'attache enfin à questionner le fait social majeur de l'éducation populaire dans l'entre-deux guerres: la prise en compte des loisirs, particulièrement sous leur forme éducative et culturelle. Par l'étude et l'analyse d'initiatives aussi variées que les loisirs dirigés, l'orientation professionnelle, l'action catholique en direction des jeunes issus des milieux ouvriers, le cinéma ou encore les danses populaires, les contributions mettent en perspective un double mouvement de diversification et de spécialisation. Il se manifeste à la fois par l'éclosion de mouvements d'enfants et de jeunes et par l'intégration de compétences techniques, quasi professionnelles.

7 À travers ce recueil d'une grande variété, l'ouvrage entend mettre l'accent sur les pratiques menées au titre de l'éducation populaire, plutôt que sur les valeurs ou les discours des acteurs. Tout en mesurant le fait que cette dissociation inscrit un point de vue particulier de l'analyse du social, considérant le discours, opposable au "faire » comme une non matérialité, elle n'en reste pas moins pertinente pour mettre en évidence, au-delà des discours, ce qui s'est fait au nom de l'éducation populaire. Elle 
permet d'interroger à la fois les controverses entre acteurs, le contenu des activités réalisées (parfois non abouties) en mesurant toutes les ambivalences de leur déploiement. Et c'est là une des grandes richesses de l'ouvrage, même si l'on pourrait regretter d'y voir faiblement développée, contrairement à ce qui est annoncé en introduction, la question des rapports entre l'école et l'éducation populaire, notamment sous l'angle de la pédagogie.

8 L'un des mérites notables de cet ouvrage réside dans l'intégration d'approches jusquelà peu mises en lumière : on pense notamment à la considération du rôle des femmes, à la fois comme militantes voire pionnières, mais aussi comme partie intégrante du peuple. Pour autant, on aurait pu souhaiter une problématisation plus poussée tant sur la faible considération, par les acteurs de l'éducation populaire de la même question de l'émancipation féminine, que du relatif vide historiographique sur la question. Une autre vertu de l'ouverture thématique est la prise en compte de la dimension internationale (un tiers de contributions) : l'enjeu poursuivi par les auteurs n'est pas de proposer une histoire internationale de l'éducation populaire mais d'éclairer la situation française par des rapprochements avec d'autres histoires nationales. Ce décentrement du regard s'avère fort bénéfique même s'il nous paraitrait intéressant d'y adosser une réflexion en termes de réseaux, de circulation transnationale des acteurs et des savoirs.

Enfin, il faut souligner que la période traitée par cet ouvrage, 1815-1945, qui précède la phase d'institutionnalisation plus souvent documentée, vient combler un manque jusque-là prégnant en terme d'analyse historiographique. On ne peut donc que se réjouir de trouver des descriptions fines et détaillées d'un vaste nombre d'activités mêlant des acteurs de l'éducation populaire dans leur grande diversité, qu'ils soient reliés aux mouvements ouvriers, aux réformateurs sociaux républicains et socialistes, aux élites religieuses, etc. Si l'ouvrage souffre parfois d'un effet patchwork, et si on aurait pu souhaiter une plus forte problématisation des productions, on ne peut que s'accorder sur la richesse de cette même pluralité, appréhendant l'éducation populaire par ses marges, ses nuances, ses aspérités. 